\title{
Short communication: Individual cow variation in urinary excretion of phosphorus
}

\author{
Peter Løvendahl*1 and Jakob Sehested† \\ *Department of Molecular Biology and Genetics, and \\ †Department of Animal Science, Aarhus University, AU-Foulum, P.O. Box 50, DK 8830 Tjele, Denmark
}

\begin{abstract}
Some dairy cows excrete large amounts of $\mathrm{P}$ through their urine; thus, it was speculated that a genetic defect related to their efficiency in uptake of $\mathrm{P}$ or recirculation of $\mathrm{P}$ could cause such an effect. This speculation was pursued in a cross sectional study on 139 cows (103 Holstein and 36 Jersey) from an experimental herd using repeated sampling of urine (301 samples) to investigate sources of variation in urinary $\mathrm{P}$ concentration $(\mathrm{Pu})$. Urine samples were taken on 6 testing sessions spread over 2 mo. Each sample was obtained by mild manual stimulation of the rear udder escutcheon area. The samples were immediately assayed for $\mathrm{pH}$, stored frozen, and assayed for inorganic $\mathrm{P}$ and creatinine. Concentrations of $\mathrm{P}$ and creatinine in urine, the ratio of $\mathrm{Pu}$ to creatinine, and $\mathrm{pH}$ were analyzed using a linear mixed model. The model included fixed effects of breed, parity number, and sampling session. Stage of lactation was fitted as Wilmink-type lactation curves. Random effects included additive polygenic ancestry, permanent animal effects, and residual. The distribution of $\mathrm{Pu}$ approximated normality except for a single sample with very high $\mathrm{Pu}$ and very low $\mathrm{pH}$. This sample came from a cow diagnosed independently with ketosis. For the remaining samples, it was shown that $\mathrm{Pu}$ has low to moderate heritability (0.12) and is only moderately repeatable (0.21). Based on a small data set, it is tentatively concluded that individual differences between cows exist in their $\mathrm{Pu}$, and individual differences presumably result from genetic differences. However, it remains unclear if cows with genetically lower or higher $\mathrm{Pu}$ will perform better on a low-P diet.
\end{abstract} Key words: phosphorus retention, urine samples, dairy cows

Received September 1, 2015.

Accepted February 11, 2016.

${ }^{1}$ Corresponding author: Peter.Lovendahl@mbg.au.dk

\section{Short Communication}

The main $\mathrm{P}$ excretion route for adult cattle is through feces, but excretion of aberrantly high amounts of $\mathrm{P}$ through urine in individual animals has been reported in the scientific literature (reviewed by Breves and Schröder, 1991). However, reports on phenotypic and genetic variation in urinary $\mathrm{P}$ excretion are scarce; therefore, the current paper focuses on phenotypic variation between individual dairy cows in urinary excretion of $\mathrm{P}$.

Urinary excretion of $\mathrm{P}$ in ruminants is usually insignificant due to efficient renal reabsorption of filtered $\mathrm{P}$. Model estimates of the urinary $\mathrm{P}$ excretion from lactating dairy cows fed dietary $\mathrm{P}$ close to their requirement are $0.002 \mathrm{~g} / \mathrm{kg}$ of BW (NRC, 2001) or $1 \%$ of absorbed $\mathrm{P}$ (Hill et al., 2008) corresponding to 1.0 to $1.4 \mathrm{~g}$ of $\mathrm{P} / \mathrm{d}$. Lower and higher urinary $\mathrm{P}$ excretions have been measured with lower respectively higher quantities of dietary P. Dietary P concentrations from 2.3 to $3.4 \mathrm{~g} /$ $\mathrm{kg}$ of $\mathrm{DM}$ did not influence the urinary $\mathrm{P}$ excretion in a long-term study with lactating dairy cows $(0.038 \mathrm{~g} / \mathrm{d}$; Puggaard et al., 2014). In a short-term study with lactating dairy cows fed varying feed forage particle size and dietary urea at a low dietary $\mathrm{P}$ concentration $(2.5$ $\mathrm{g} / \mathrm{kg}$ of DM) urinary P excretion was $0.035 \mathrm{~g} / \mathrm{d}$ (Puggaard et al., 2013). Urinary excretion was 0.27 to 0.43 $\mathrm{g}$ of $\mathrm{P} / \mathrm{d}$ in dairy cows 3 to $11 \mathrm{wk}$ in lactation when fed $0.34 \%$ dietary $\mathrm{P}, 0.58$ to $1.63 \mathrm{~g}$ of $\mathrm{P} / \mathrm{d}$ when cows were fed $0.51 \%$ dietary $\mathrm{P}$, and 2.26 to $6.08 \mathrm{~g}$ of $\mathrm{P} / \mathrm{d}$ when cows were fed $0.67 \%$ dietary P (Knowlton and Herbein, 2002). Similar effects of dietary $P$ on mean urinary $P$ excretion were observed in more studies (Morse et al., 1992; Wu et al., 2001), although a lower excretion was found in other studies (Odongo et al., 2007; Ferris et al., 2010).

Urinary $\mathrm{P}$ excretion can become quantitatively significant in case of high plasma $\mathrm{P}$ concentrations (approximately $2 \mathrm{mmol} / \mathrm{L}$ ) or if saliva secretion is inhibited by feeding diets low in physical fiber (Scott et al., 1985; Scott, 1988; Scott and Buchan, 1988; Knowlton 
and Herbein, 2002; Bravo et al., 2003; Wu, 2005; Hill et al., 2008). Several studies have reported the occurrence of one or a few experimental animals with exceptionally high urinary $\mathrm{P}$ excretion not related to any of the mentioned causes (reviewed by Breves and Schröder, 1991). Manston and Vagg (1970) concluded that a small proportion of cows have a tendency to excrete relatively large amounts of phosphate in the urine, and similar observations were reported in newer studies with highyielding dairy cows (Wu et al., 2000). Genetic variation in urinary $\mathrm{P}$ was detected in an experiment with 4 sets of triplet lambs (Field et al., 1984; Field and Woolliams, 1984) and individual differences were reported by Sato (1981) in sheep and goats. A genetic predisposition to deviating high urinary $\mathrm{P}$ might be caused by single gene mutations or be caused by polygenic quantitative genetic variation. In either case, individual animals will have urine $\mathrm{P}$ concentrations that are less variable compared with randomly taken samples, and concentrations are therefore repeatable.

We hypothesized that urinary $\mathrm{P}$ concentrations $(\mathbf{P u})$ would be normally distributed except if some individual animals have aberrantly high $\mathrm{Pu}$. The objectives of the present study were to estimate individual and genetic cow variation in $\mathrm{Pu}$, and to detect cows with aberrant $\mathrm{Pu}$.

This experiment used repeated sampling of urine from a cross section of cows at the Danish Cattle Research Centre (Foulum, Denmark; Table 1). The cows were sampled during 6 testing sessions (January to March 2009, 2-wk intervals) with the aim of obtaining on average 2 samples per cow to allow for studying repeatabil- ity. Each sample only took few minutes to obtain and each testing session lasted less than $2 \mathrm{~h}$, during which as many cows as possible were sampled. The lactating cow herd (5-391 DIM) contained 2 groups of Holsteins (103 sampled cows) and 1 group of Jerseys (36 cows sampled). Each group was assigned to an automated milking system (VMS, DeLaval, Tumba, Sweden). All cows were fed a partially mixed ration, which was fed ad libitum (DM composition: $36.7 \%$ maize silage, $35.5 \%$ grass silage, $11.4 \%$ rolled barley, $8.9 \%$ soy expeller, $5.8 \%$ canola expeller, $1.7 \%$ mineral and salt mix), and supplementary concentrates during milking restricted to total $3 \mathrm{~kg} / \mathrm{d}$. The total feed intake from the mixed ration (Insentec, RIC-system, Marknesse, the Netherlands) and of concentrates provided to cows was $19.4 \pm$ $5.9 \mathrm{~kg}$ of $\mathrm{DM} / \mathrm{d}$ (mean $\pm \mathrm{SD}$ for all cows across breeds) containing $4.04 \mathrm{~g}$ of $\mathrm{P} / \mathrm{kg}$ of $\mathrm{DM}$. The $\mathrm{P}$ content in feed was determined from composition and assayed content in ingredients. Daily milk yield on each test day was used as a reference trait to compare with urine-based traits.

Urine samples from 139 cows were used for the present study, covering all stages of lactation and parities from 1 to 5 (Table 1$)$. Urine samples $(100 \mathrm{~mL})$ were obtained following mild manual stimulation of the rear udder escutcheon area, or in some cases without stimulation. Sampling sessions lasted up to $2 \mathrm{~h}$. Urinary $\mathrm{pH}$ was measured immediately after sampling (HI-98127, Hanna Instruments Inc., Woonsocket, RI), before aliquots were transferred to 5 -mL tubes (Sarstedt AG \& Co, Nümbrecht, Germany), and stored frozen $\left(-25^{\circ} \mathrm{C}\right)$ until assayed.

Table 1. Data overview and estimates of fixed effects and random variance parameters for concentrations of $\mathrm{P}$ and creatinine in urine of dairy cows

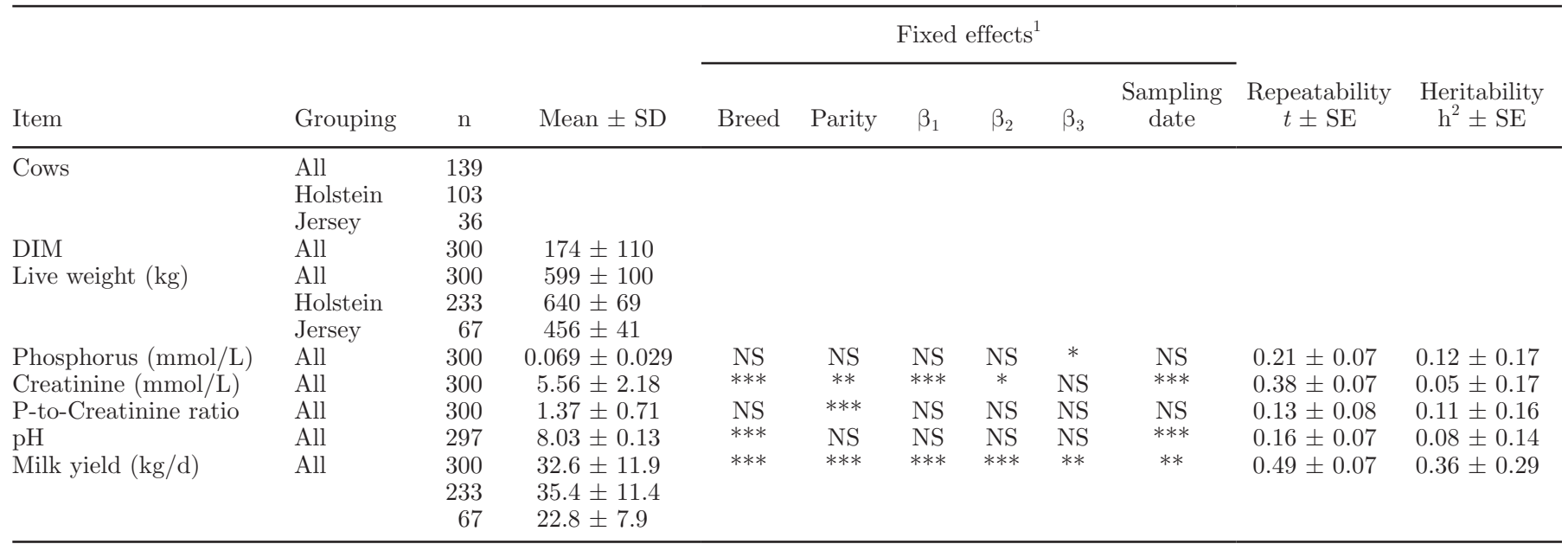

${ }^{1}$ F-test for fixed effects.

${ }^{*} P<0.05,{ }^{* *} P<0.01,{ }^{* * *} P<0.001$. 
Urine was assayed for concentration of inorganic phosphorus (mmol/L) using an ammonium molybdatebased kit (Cobas PHOS kit, Roche Diagnostics GmbH, Mannheim, Germany; on a Roche-Hitachi 912 autoanalyzer). Urine was also assayed for concentration of creatinine (CREATu; mmol/L) using an enzymatic colorimetric kit. Assays for Pu and CREATu both had total coefficient of variation below $2.5 \%$ based on 2 reference samples.

The $\mathrm{Pu}, \mathrm{CREATu}$, the ratio between $\mathrm{Pu}$ and CREA$\mathrm{Tu}$, and urine $\mathrm{pH}$ value were used as response variables. The variables were approximately normally distributed and transformation was not imposed before ANOVA. One sample deviating strongly in both $\mathrm{pH}$ and $\mathrm{Pu}$ was detected and omitted from further analysis because the cow was independently diagnosed with ketosis on that day.

A linear mixed model was fitted to each variable to estimate fixed effects of stage of lactation, breed, sampling day, parity, and random variance belonging to individual cows $\left(\sigma_{\text {cow }}^{2}\right)$. For the genetic analysis, ancestral relationships between animals were obtained by tracing their parentage at least 3 generations back through the national database. The between-cow variance $\left(\sigma_{\text {cow }}^{2}\right)$ component was further partitioned into additive genetic background $\left(\sigma_{a}^{2}\right)$ and the permanent environment $\left(\sigma_{p e}^{2}\right)$ of that particular animal:

$$
\begin{aligned}
& y_{i j k l m}=\alpha+\beta_{1} e^{-0.05 t}+\beta_{2} t+\beta_{3} t+\mathrm{DATE}_{t} \\
& +\operatorname{BREED}_{j}+\operatorname{PARITY}_{k}+\mathrm{COW}_{j k l}+\varepsilon_{i j k l m},
\end{aligned}
$$

where $y$ was one of the response variables at a time and $\alpha$ is the intercept. The systematic factors were sampling session $\left(\mathrm{DATE}_{i}, 6\right.$ levels), breed $\left(\mathrm{BREED}_{j}\right.$, Holstein or Jersey), parity $\left(\right.$ PARITY $_{k}, 1,2$, and $\geq 3$ ), cow $\left(\mathrm{COW}_{j k l}\right)$, and sample $(m)$, and $\varepsilon_{i j k l m}$ is the error term. Stage of lactation was modeled as a continuous curve with 3 coefficients on DIM $\left(t ; \beta_{1}, \beta_{2}, \beta_{3}\right)$ as also used for milk yield (Wilmink, 1987). Random variance from cows $\left(\sigma_{\text {cow }}^{2}\right)$ and residual $\left(\sigma_{e}^{2}\right)$ were assumed normally distributed. Variance components were used to calculate repeatability as the intraclass correlation for cows,

$$
t=\sigma_{\mathrm{cow}}^{2} /\left(\sigma_{\mathrm{cow}}^{2}+\sigma_{e}^{2}\right),
$$

being a measure of individuality. From the variance components the heritability coefficient was calculated as

$$
h^{2}=\sigma_{a}^{2} /\left(\sigma_{a}^{2}+\sigma_{p e}^{2}+\sigma_{e}^{2}\right) .
$$

The ANOVA and variance component estimates were obtained using the MIXED procedure of SAS (SAS Institute Inc., Cary, NC), and the software package DMU (Madsen and Jensen, 2013).

One urine sample was omitted from further statistical analysis, as the cow was diagnosed as ketotic on the day of sampling due to highly elevated milk levels of BHB detected by the HerdNavigator herd management system (Lattec, Hillerød, Denmark). This sample also had very low $\mathrm{pH}$ (5.9) and extremely high values for $\mathrm{Pu}(2.05 \mathrm{mmol} / \mathrm{L})$ and CREATu $(2.98 \mathrm{mmol} / \mathrm{L})$. Cattle on energy-rich diets low in fiber and high in starch have previously been reported to have disturbed rumen function leading to acidosis with low $\mathrm{pH}$ in urine and also with high $\mathrm{Pu}$, as seen in steers (Reed et al., 1965). However, it is not known if the phosphate in urine has a specific role as buffer or if it is leaked for another purpose (Bravo et al., 2003). However, studies on anioncation balance have also shown effects on $\mathrm{Pu}$ and on $\mathrm{pH}$ in urine (Ramos-Nieves et al., 2009; Grünberg et al., 2011); thus, $\mathrm{pH}$ and $\mathrm{pU}$ may be useful as indicators of mineral supply. For our study it was important to have the $\mathrm{pH}$ values of urine samples available to correctly classify this sample as caused by ketosis rather than confusing it with a genetic defect.

The distribution of $\mathrm{Pu}$ in Holstein and Jersey cows resembled normality (visual inspection of distribution plots), with a somewhat right-skewed distribution. It was also clear that some cows had very low Pu. Distributions for CREATu in Jersey and Holstein differed because of different mean values. The ratio of $\mathrm{Pu}$ to CREATu had skewed distributions, probably as a result of the way this ratio is calculated and the distributions of the 2 variables going into the ratio.

The excretion of $\mathrm{P}$ through urine in dairy cows accounts for only a small fraction of the total P excreted, and $\mathrm{Pu}$ will be low (Scott et al., 1985; Scott and $\mathrm{Bu}-$ chan, 1988; Knowlton and Herbein, 2002; Bravo et al., 2003; Hill et al., 2008). However, many dairy herds are oversupplied with P (Powell et al., 2002; Rotz et al., 2002) as compared with recommended dietary $\mathrm{P}$ concentrations (NRC, 2001), leading to higher concentrations of $\mathrm{P}$ in plasma and urine (Scott et al., 1985; Challa and Braithwaite, 1988; Scott, 1988). Increased $\mathrm{Pu}$ has also been observed in animals where saliva secretion is inhibited by feeding diets low in physical fiber (Scott et al., 1985; Scott and Buchan, 1988; Knowlton and Herbein, 2002; Bravo et al., 2003; Hill et al., 2008).

The systematic change in $\mathrm{Pu}$ over the lactation was quantitatively small (Figure 1). However, a decrease in $\mathrm{Pu}$ was found in early lactation, followed by a slow and small incline until about 7 mo in lactation, when concentrations decreased again. Only the decrease in 
late lactation was significant (Table 1). In contrast, CREATu decreased in early lactation to reach a nadir at around 50 DIM, followed by a slow increase over the rest of the lactation (Table 1). Consequently, the ratio between $\mathrm{Pu}$ to CREATu increased in early lactation to reach a plateau between 90 and 180 DIM before it decreased toward the end of lactation. The $\mathrm{pH}$ value was stable throughout lactation (data not shown). In other studies, CREATu has been used to adjust $\mathrm{Pu}$ concentrations by expressing those as ratios (Estermann et al., 2002). In the current study, CREATu was strongly influenced by stage of lactation effects, more than the $\mathrm{Pu}$ concentrations themselves, so that the ratio was also affected by stage of lactation. Consequently, the ratio between $\mathrm{Pu}$ to $\mathrm{CREATu}$ was not more useful for studying urinary $\mathrm{P}$ excretion than $\mathrm{Pu}$ concentrations themselves.

Holstein and Jersey cows did not differ significantly in $\mathrm{Pu}$. Holsteins had significantly higher CREATu than Jerseys $(P<0.001$; Table 1$)$, and consequently the $\mathrm{Pu}-$ to-CREATu ratio was higher in Jersey than in Holstein. Jersey cows had 0.09 units higher urinary $\mathrm{pH}$ than Holstein cows $($ Jersey $=8.10 \pm 0.02 ;$ Holstein $=8.01 \pm$
0.02; $P<0.01$; Table 1 ). Parity only affected CREATu with the highest concentrations in young cows (parity 1) and no difference between second and later parities.

We found no indication of a specific subpopulation of samples with either high or low $\mathrm{Pu}$ values, except for the one sample from the ketotic cow. The effect of individuals on the concentration of $\mathrm{Pu}$ expressed as the repeatability was moderate $(t=0.21$; Table 1$)$; likewise, CREATu was moderately repeatable. The urinary $\mathrm{pH}$ had lower repeatability than $\mathrm{Pu}$ and CREATu; in comparison, milk yield had the highest repeatability $(t=$ 0.49 ). The heritability estimate for milk yield was 0.36 , which was higher than the estimates for $\mathrm{Pu}, \mathrm{CREATu}$, and $\mathrm{pH}$ (range $=0.05-0.12$; Table 1 ). Standard errors of heritability estimates were in the range between 0.14 and 0.29 for all variables; thus, these preliminary heritability estimates should only be viewed as indications. The results of our study showed that cows had large individual variation in their $\mathrm{Pu}$ concentration, and that a large part of the individual variation was likely to have an additive genetic background. However, the estimated heritability of $\mathrm{Pu}$ concentration was lower than heritability estimates from sheep studies (Field

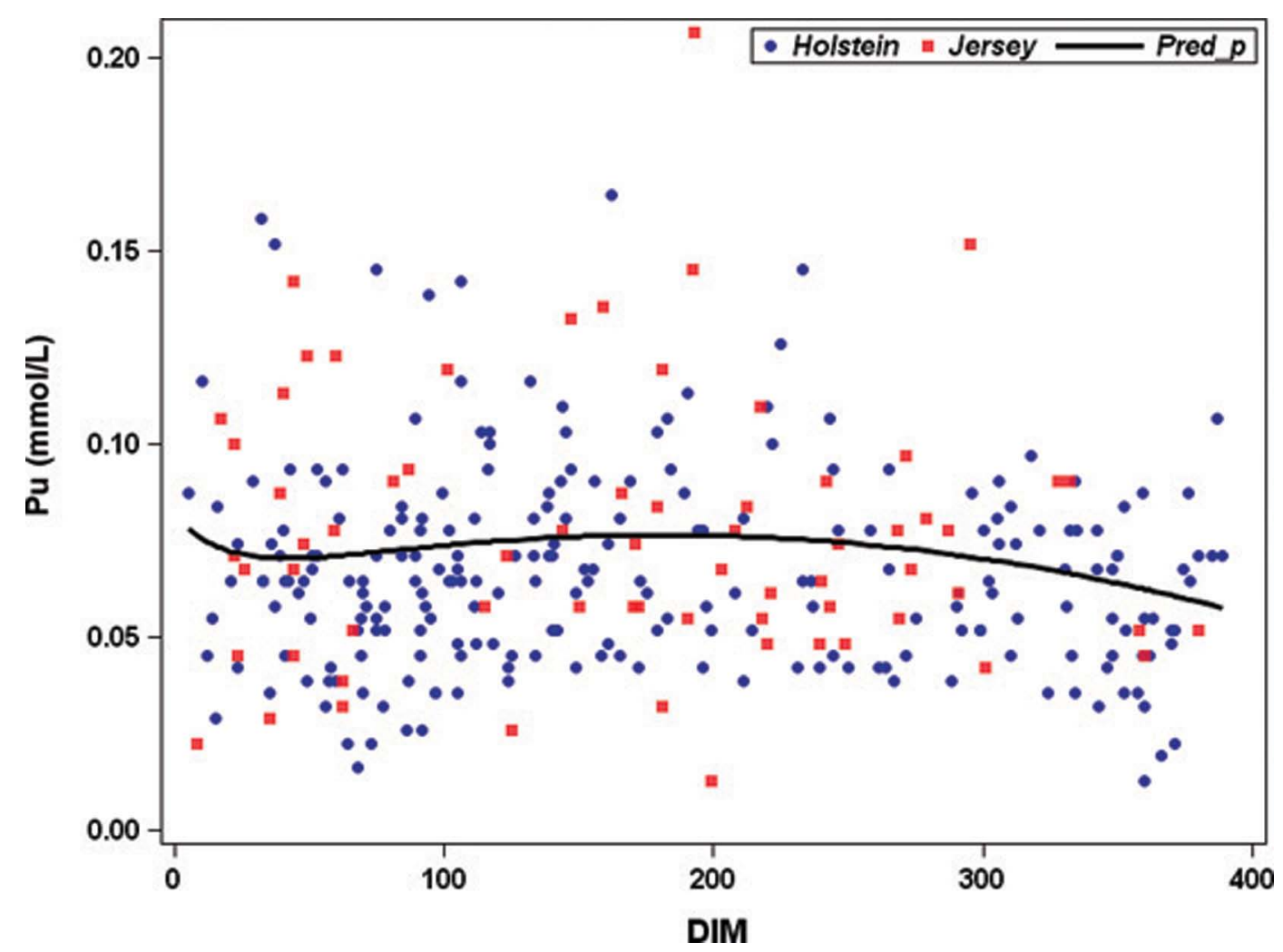

Figure 1. Concentrations of urinary $\mathrm{P}(\mathrm{Pu})$ from Holstein and Jersey cows at various stages of lactation (DIM), together with an overall fitted curve using model 1 (Pred_P). The outlier with $2.05 \mathrm{mmol} / \mathrm{L}$ of $\mathrm{Pu}$ from a ketotic cow as described in the text was excluded from this figure. Color version available online. 
and Woolliams, 1984) and could not be compared with a study in goat and sheep that did not quantify individual or genetic variation (Sato, 1981). Heritability estimates for $\mathrm{Pu}$ based on cattle data are scarce, and the present results are in support of the previous findings in sheep, jointly indicating that $\mathrm{Pu}$ is a moderately repeatable trait and that genetic variation is the basis of the individual differences. However, we found no obvious indication of $\mathrm{Pu}$ being severely affected by strong single gene effects, as the only very high $\mathrm{Pu}$ value detected could be traced back to a case of ketosis. Thereby, our study does not indicate a genetic defect leading to the urinary excretion of large amounts of $\mathrm{P}$ in dairy cows.

The current study was based on data from a single experimental herd with repeated cross-sectional spot sampling from a small cohort of high-yielding cows of 2 breeds. To obtain reliable genetic parameters, data from larger cohorts are needed. The relative ease with which urine samples were collected using manual stimulation seemed effective for such a purpose and involved only very mild interactions with the cows; as such it is widely applicable. A further application might be in monitoring mineral supply and anion-cation balance in diets. Given the low repeatability, experimental power in any study is greatly enhanced by repeated sampling of each cow.

In conclusion, individual differences between cows were detected in their urine $\mathrm{P}$ concentrations, and individual differences are presumably anchored in genetic differences. We saw no indications that individual dairy cows consistently excrete very large amounts of phosphorus. Creatinine-to-Pu ratio was not useful for studying $\mathrm{Pu}$ excretion due to stage of lactation effects on creatinine concentrations. The $\mathrm{Pu}$ concentrations are seen as indicators of $\mathrm{P}$ recycling and absorption efficiency. Thereby, a subject for further research would be to investigate if genetic selection for cows demanding less $\mathrm{P}$ in diets is possible and feasible.

\section{ACKNOWLEDGMENTS}

The authors are grateful to personnel at Danish Cattle Research Centre (Foulum, Denmark) and to master's student Vibeke Duchwaider (Aarhus University, Tjele, Denmark) for careful help with urine sampling, and to laboratory technician Gunhild Ladehoff (Aarhus University, Tjele, Denmark) for assaying samples. Funding was provided by The Ministry of Food, Agriculture and Fisheries (Copenhagen, Denmark), The Danish AgriFish Agency (Copenhagen, Denmark), and Department of Animal Science, Aarhus University (Foulum, Denmark).

\section{REFERENCES}

Bravo, D., D. Sauvant, C. Bogaert, and F. Meschy. 2003. III. Quantitative aspects of phosphorus excretion in ruminants. Reprod. Nutr. Dev. 43:285-300.

Breves, G., and B. Schröder. 1991. Comparative aspects of gastrointestinal phosphorus metabolism. Nutr. Res. Rev. 4:125-140.

Challa, J., and G. D. Braithwaite. 1988. Phosphorus and calcium metabolism in growing calves with special emphasis on phosphorus homoeostasis. 1. Studies of the effect of changes in the dietary phosphorus intake on phosphorus and calcium metabolism. J. Agric. Sci. 110:573-581.

Estermann, B. L., F. Sutter, P. O. Schlegel, D. Erdin, H.-R. Wettstein, and M. Kreuzer. 2002. Effect of calf age and dam breed on intake, energy expenditure, and excretion of nitrogen, phosphorus, and methane of beef cows with calves. J. Anim. Sci. 80:1124-1134.

Ferris, C. P., M. A. McCoy, D. C. Patterson, and D. J. Kilpatrick. 2010. Effect of offering dairy cows diets differing in phosphorus concentration over four successive lactations: 2. Health, fertility, bone phosphorus reserves and nutrient utilisation. Animal 4:560571.

Field, A. C., and J. A. Woolliams. 1984. Genetic control of phosphorus metabolism in sheep. Can. J. Anim. Sci. 64(Suppl.):232-233.

Field, A. C., J. A. Woolliams, R. A. Dingwall, and C. S. Munro. 1984. Animal and dietary variation in the absorption and metabolism of phosphorus by sheep. J. Agric. Sci. 103:283-291.

Grünberg, W., S. S. Donkin, and P. D. Constable. 2011. Periparturient effects of feeding a low dietary cation-anion difference diet on acidbase, calcium, and phosphorus homeostasis and on intravenous glucose tolerance test in high-producing dairy cows. J. Dairy Sci. 94:727-745.

Hill, S. R., K. F. Knowlton, E. Kebreab, J. France, and M. D. Hanigan. 2008. A model of phosphorus digestion and metabolism in the lactating dairy cow. J. Dairy Sci. 91:2021-2032.

Knowlton, K. F., and J. H. Herbein. 2002. Phosphorus partitioning during early lactation in dairy cows fed diets varying in phosphorus content. J. Dairy Sci. 85:1227-1236.

Madsen, P., and J. Jensen. 2013. DMU: A User's Guide. A package for analysing multivariate mixed models. Accessed Oct. 17, 2015. http://dmu.agrsci.dk/DMU/doc/.

Manston, R., and M. J. Vagg. 1970. Urinary phosphate excretion in dairy cow. J. Agric. Sci. 74:161-167.

Morse, D., H. H. Head, C. J. Wilcox, H. H. van Horn, C. D. Hissem, and B. Jr. Harris. 1992. Effects of concentration of dietary phosphorus on amount and route of excretion. J. Dairy Sci. 75:30393049 .

NRC. 2001. Nutrient Requirements of Dairy Cattle. 7th rev. ed. Natl. Acad. Press, Washington, DC.

Odongo, N. E., D. McKnight, A. KoekKoek, J. W. Fisher, P. Sharpe, E. Kebreab, J. France, and B. W. McBride. 2007. Long-term effects of feeding diets without mineral phosphorus supplementation on the performance and phosphorus excretion in high-yielding dairy cows. Can. J. Anim. Sci. 87:639-646.

Powell, J. M., D. B. Jackson-Smith, and L. D. Satter. 2002. Phosphorus feeding and manure nutrient recycling on Wisconsin dairy farms. Nutr. Cycl. Agroecosyst. 62:277-286.

Puggaard, L., N. B. Kristensen, and J. Sehested. 2013. Effect of feed forage particle size and dietary urea on excretion of phosphorus inlactating dairy cows. Livest. Sci. 158:50-56.

Puggaard, L., P. Lund, A. Liesegang, and J. Sehested. 2014. Long term effect of reduced dietary phosphorus on feed intake and milk yield in dry and lactating dairy cows. Livest. Sci. 159:18-28.

Ramos-Nieves, J. M., B. J. Thering, M. R. Waldron, P. W. Jardon, and T. R. Overton. 2009. Effects of anion supplementation to lowpotassium prepartum diets on macromineral status and performance of periparturient dairy cows. J. Dairy Sci. 92:5677-5691.

Reed, W. D. C., R. C. Elliott, and J. H. Topps. 1965. Phosphorus excretion of cattle fed on high-energy diets. Nature 208:953-954.

Rotz, C. A., A. N. Sharpley, L. D. Satter, W. J. Gburek, and M. A. Sanderson. 2002. Production and feeding strategies for phosphorus management on dairy farms. J. Dairy Sci. 85:3142-3153. 
Sato, H. 1981. Effect of feedingon diurnal variation in urinary phosphorus excretion in goats and sheep. Nihon Juigaku Zasshi 43:915917.

Scott, D. 1988. Control of phosphorus balance in ruminants. Pages 156-174 in Aspects of Digestive Physiology in Ruminants. A. Dobson and M. J. Dobson, ed. Cornell University Press, Ithaca, NY.

Scott, D., and W. Buchan. 1988. The effects of feeding pelleted diets made from either coarsely or finely ground hay on phosphorus balance and on the partition of phosphorus excretion between urine and feces in the sheep. Q. J. Exp. Physiol. 73:315-322.

Scott, D., F. G. Whitelaw, W. Buchan, and L. A. Bruce. 1985. The effect of variation in phosphorus intake on salivary phosphorus secretion, net intestinal phosphorus absorption and faecal endogenous phosphorus excretion in sheep. J. Agric. Sci. 105:271-277.
Wilmink, J. B. M. 1987. Adjustment of test-day milk, fat and protein yield for age, season and stage of lactation. Livest. Prod. Sci. $16: 335-348$.

$\mathrm{Wu}, \mathrm{Z} .2005$. Utilization of phosphorus in lactating cows fed varying amounts of phosphorus and sources of fiber. J. Dairy Sci. 88:28502859.

Wu, Z., L. D. Satter, A. J. Blohowiak, R. H. Stauffacher, and J. H. Wilson. 2001. Milk production, estimated phosphorus excretion, and bone characteristics of dairy cows fed different amounts of phosphorus for two or three years. J. Dairy Sci. 84:1738-1748.

Wu, Z., L. D. Satter, and R. Sojo. 2000. Milk production, reproductive performance, and fecal excretion of phosphorus by dairy cows fed three amounts of phosphorus. J. Dairy Sci. 83:1028-1041. 